\title{
Immunophenotypic study of acute leukemia by flow cytometry at BPKMCH.
}

\author{
Shrestha $\mathrm{S}^{1}$, Shrestha $\mathrm{J}^{2}$, Pun C.B ${ }^{1}$, Pathak $\mathrm{T}^{1}$, Bastola $\mathrm{S}^{1}$, Bhatta $\mathrm{R}^{1}$ \\ ${ }^{I}$ Departments of Pathology, BP Koirala Memorial Cancer Hospital, Bharatpur, Nepal \\ ${ }^{2}$ Departments of Medical Oncology, BP Koirala Memorial Cancer Hospital, Bharatpur, Nepal
}

\section{Keywords: \\ Acute leukemia; Flow cytometry; Immunophenotype}

\begin{abstract}
Background: Immunophenotyping of acute leukemia is one of the most important clinical applications of flow cytometry. The aim of this study was to determine the immunophenotyping profile of acute leukemia, by means of a flow cytometric method, using monoclonal antibodies all marked with a fluorochrome, in four colour systems to assess their distribution according to type of leukemia (lymphoid $\mathrm{B}$ or $\mathrm{T} /$ myeloid).
\end{abstract}

Materials and Methods: We retrospectively collected data of immunophenotyping from 52 acute leukemia patients at the department of pathology in B.P. Koirala Memorial Cancer Hospital from January 2010 to December 2011. Diagnosis was based on peripheral blood and bone marrow examination for morphology, cytochemistry and immunophenotypic studies.

Results: Out of total 52 cases of acute leukemia diagnosed by flow cytometry over a two year period, there were 31 cases $(59.6 \%)$ of acute lymphoblastic leukemia, 20 cases $(38.4 \%)$ of acute myelogenous leukemia and one case (1.9\%) of bi-phenotypic acute leukemia. Leukemia was diagnosed among adults in $44.2 \%$ whereas among children with age less than or equal to 15 years in $55.7 \%$. Thirty eight $(73 \%)$ were male and $14(27 \%)$ were female with a male: female ratio of $2.7: 1$. For acute myelogenous leukemia, it was found that M0 (5.0\%), M1 (20\%), M2 (60\%), M3 (15\%), M4 (5.0\%) were detected. CD13 and CD33 were the most useful markers in the diagnosis of acute myelogenous leukemia. The most common subtype was AML-M2. Of the 31 cases with acute lymphoblastic leukemia, 20 cases $(64.5 \%)$ were identified as B-ALL and 11 cases (35.5\%) as T-ALL. Aside from cytoplasmic CD3 (cCD3) and CD7 were the most sensitive antigens present in all cases of T-ALL. All cases of B-ALL showed expression of pan B-cell markers CD19 and CD22, but 15 (75\%) of 20 cases expressed CD10.

Conclusion: Flow cytometric immunophenotyping was found to be especially useful in the correct identification and diagnosis of acute myeloid or lymphoblastic leukemia and its subtypes. In combination with French-American-British (FAB) morphology and immunophenotyping, we were able to diagnose and classify all patients with acute leukemia in this study.

\section{INTRODUCTION}

Acute leukemia comprises a heterogeneous group of diseases characterized by rapid and uncontrolled clonal

\section{Correspondence:}

Dr. Sadina Shrestha, MD

Junior Consultant, Department of Pathology,

B. P. Koirala Memorial Cancer Hospital, Bharatpur, Chitwan, Nepal

Email: sadina_shrestha@yahoo.com expansion of progenitor cells of the hematopoietic system. ${ }^{1}$ Hallmark for the diagnosis of acute leukemia, until recent past, has been the morphology and cytochemistry. They provide correct diagnosis in about $80 \%$ of the cases. For instance, Jawaid et al. in their series reported that $11 \%$ cases of acute leukemia's were unidentifiable in terms of their phenotype while $9 \%$ were identified incorrectly on morphological basis, all of which were correctly allocated to their lineages after flow cytometric analysis. ${ }^{2}$ Thus, major developments in the field of immunology have now brought 
an era of diagnosing acute leukemias by means of flow cytometry. The ability of immunophenotyping to identify myeloid versus lymphoid differentiation approaches $98 \%{ }^{3}$

The immunophenotypic studies of acute leukemia by flow cytometry have become a powerful tool for proper identification of myeloid or lymphoid lineage. Therefore, it has great prognostic and therapeutic implications. ${ }^{4}$ Not only acute myeloid leukemia can be differentiated from the acute lymphoblastic leukemia (ALL) but B-cell or T-cell lineages can also be determined which cannot be achieved by morphology and cytochemistry alone., ${ }^{2,5}$ Immunophenotyping is also essential for recognizing several subtypes of acute myeloid leukemia and biphenotypic acute leukemias.

The flow cytometry study of acute leukemia samples started first time in Nepal at the department of pathology, BPKMCH Bharatpur, Chitwan from January 2010. Since then there has been continuous evaluation of the panel of the antibodies used to study the leukemic cells.

\section{MATERIALS AND METHODS}

A total of 214 cases of acute leukemia were diagnosed at BP Koirala Memorial Cancer Hospital between over a period of two years between Jan. 2010 and Dec.2011. However, immunophenotyping was performed on only 52 cases. Acute leukemia was classified on the basis of standard morphological and cytochemical criteria of the FrenchAmerican-British cooperative study groups. ${ }^{6}$ Immunological classification of acute leukemia was assessed using a four line panel of monoclonal antibody for phenotying leukemic blasts cells. $^{7}$ We found 20 cases of B-cell lineage acute lymphoblastic leukemia , 11 cases of T-cell ALL, 20 cases of acute myeloid leukemia and one case of biphenotypic leukemia.

\section{Morphology and Cytochemistry}

All specimens were obtained and prepared for morphologic examination using standard techniques. Bone marrow aspirate smear and peripheral blood specimen were air dried and stained with May-Grünwald Giemsa (MGG) stain technique and examined under light microscopy. Cytochemical staining of myeloperoxidase (MPO) and periodic acid- shiff (PAS) stain were done in all cases of acute leukemia.

\section{Methodology for immunophenotyping}

Samples of peripheral blood $(n=12)$ or bone marrow $(n=40)$ were collected in ethylene diamine tetraacetic acid (EDTA) for immunophenotyping. The samples were processed within twenty four hours of collection. For the immunophenotypic diagnosis of acute leukemias, various combinations of fluorochrome-conjugated monoclonal antibodies $(\mathrm{MoAb})$ per tube were added to the samples. All the MoAbs were obtained from Becton Dickinson (California, United States). They were conjugated with fluorescein isothiocyanate (FITC), phycoerythrin (PE) or peridinin chlorophyll protein (PerCP), and were directed to antigens for $\mathrm{T}$ cells (CD2, cytoplasmic (c) CD3, CD4, CD5, CD7 and CD8), B cells (CD10, CD19, cCD22 and cCD79a), myeloid cells [CD13, CD33, CD117 and cyto myeloperoxidase (MPO)], monocytes (CD14 and CD64), non-specific lineage pan-leukocytes (CD45) and precursor cells [CD34 and human leukocyte antigen-DR (HLA-DR)].

Membrane and intracytoplasmic labeling was performed using $1 \times 10^{6}$ cells per tube. For membrane labeling, the samples were incubated with each antibody for 10 to 15 minutes. The erythrocytes were lysed with $2 \mathrm{ml}$ of FACS lysing solution (Becton Dickinson, California, U.S), diluted to $1: 10$ and then washed with $2 \mathrm{ml}$ of phosphate-buffered saline (PBS; $\mathrm{pH}=7.2$ ). For intracytoplasmic labeling, FACS permeabilizing solution (Becton Dickinson) was used in accordance with the manufacturer's instructions.

Data acquisition and sample analysis was performed in a BD FACS Caliber (4- color, Becton Dickinson, USA), using the Cell Quest software (Becton Dickinson), after calibration with the Calibrate bead kit (Becton Dickinson).

The blast gating strategy included using dot plots of CD45 expression versus intracellular complexity (side scatter angle, SSC) and also a second gate considering cell size (forward scatter angle, FSC) versus SSC. A total of 10,000 events were acquired in the target gate. Antigen was considered as positive if $20 \%$ or more of the blast cells reacted with a particular antibody.

\section{RESULTS}

Based on the morphology, FAB criteria, and immunophenotyping, the 52 cases were classified as follows: 31(59.6\%) ALL, 20 (38.4\%) AML and 1 (2.0 $\%$ ) biphenotypic leukemia. (Table 1). We found 20 cases (64.5\%) of B- cell lineage ALL (fig.1), which included 15 cases $(75 \%)$ of CD10+ve ALL, 5 cases $(25 \%)$ of CD10-ve ALL and 11 cases (35.5\%) of T cell ALL (fig.2). B-ALL could not be sub-classified in terms of the phase of maturation due to unavailability of some antibodies. We considered them as Common ALL (CD10+) and Null-ALL (CD10-). (Table 3) The subtypes based on CALLA (CD10) are useful in prognosis. The percentages of ALL for children and adults were $72.4 \%$ and $43.5 \%$, respectively while that of AML for children and adults were $27.6 \%$ and $52.2 \%$, respectively. (Table 1)

Twenty cases of AML (fig.3) were classified according to the FAB guidelines as follows: M0 one case $(5.0 \%), \mathrm{M} 1$ four cases (20\%), M2 twelve cases (60\%), M3 three cases (15\%), M4 one case $(5.0 \%)$. (Table 2) No cases were positive for 
M5, M6 and M7. There were more male patients affected by acute leukemia $(38 / 52$ or $73 \%)$ than females $(14 / 52$ or $27 \%$ ). (Table 4$)$ Twenty nine cases $(55.7 \%)$ were children i.e. less than or equal to 15 years while there were $23(44.2$ $\%$ ) adults. (Table1) The commonest FAB subtype, in both children and adults, was AML-M2 (50\%). The positivity of stem cell marker CD34 was seen in the range of 5\% to 50 $\%$ among various subtypes. The highest positivity was seen in M0 and M1 FAB subtype. The expression of CD13 and CD33 was observed in almost all cases of AML subtype. The expression of MPO was seen only $1 \%$ in AML M0.

There was also lack of expression of $\mathrm{B}$ and $\mathrm{T}$ cell makers like cyCD3 and cyCD79a in AML M0. HLA-DR is present in most acute leukemias, except T-ALL and AML M3. The myelomonocytic leukemia (AML-M4) shows expression of CD14 and CD36 (not shown in Table 2).

All cases of B-ALL showed expression of B-cell markers
cyCD22 (100\%) and CD19 (85\%) respectively. CD10 and the immature cell marker HLA-DR presented positivity rates of $75 \%$ and $85 \%$ respectively. Aside from cytoplasmic CD3 and CD7 were the most sensitive antigens present in all 11 cases of T-ALL. One case of biphenotypic acute leukemia showed expression of both cyMPO and cyCD3 in addition to CD34, HLA-DR, CD13, CD117, CD2, CD3 and CD7. In our study, aberrant expression of lymphoid antigen was seen in 6/20 cases (30\%) of AML. CD7 was the most commonly expressed lymphoid marker 4/20 (20\%) followed by $1 / 20(5 \%)$ CD22 and 1/20(5\%) CD3. Aberrant expression of myeloid antigens CD13 and CD33 were seen in $4 / 31(12.9 \%)$ and $1 / 31(3.2 \%)$ cases of ALL respectively. The most frequent marker was CD13.

Detection of intracelullar myeloperoxidase (MPO), cyCD13, cyCD79a, cyCD22, and cyCD3 has become the most specific tool for the assignment of myeloid (MPO and cyCD13), B (cyCD79a and cyCD22) and T lymphoid

Table 4: Total No. of male/ female ratio in AML/ALL

Table 1: Frequency of each type of acute leukemia, according to age group

\begin{tabular}{cccc}
\hline $\begin{array}{c}\text { Types of acute } \\
\text { leukemia }\end{array}$ & $\begin{array}{c}\text { children (n=29) } \\
\mathbf{n}(\mathbf{\%})\end{array}$ & $\begin{array}{c}\text { Adult }(\mathbf{n = 2 3}) \\
\mathbf{n}(\mathbf{\%})\end{array}$ & $\begin{array}{c}\text { Total }(\mathbf{n}=\mathbf{5 2}) \\
\mathbf{n}(\mathbf{\%})\end{array}$ \\
\hline $\begin{array}{c}\text { Acute Myeloid } \\
\text { leukemia }\end{array}$ & $8(27.6 \%)$ & $12(52.2 \%)$ & $20(38.4 \%)$ \\
$\begin{array}{c}\text { Acute Lympho- } \\
\text { blastic leukemia }\end{array}$ & $21(72.4 \%)$ & $10(43.5 \%)$ & $31(59.6 \%)$ \\
$\begin{array}{c}\text { Biphenotypic } \\
\text { leukemia }\end{array}$ & - & $1(4.3 \%)$ & $1(2 \%)$ \\
\hline
\end{tabular}

\begin{tabular}{cccc}
\hline & $\begin{array}{c}\text { Males }(\mathrm{n}=38) \\
\mathrm{n}(\%)\end{array}$ & $\begin{array}{c}\text { Females } \\
(\mathbf{n = 1 4}) \mathbf{n}(\mathbf{\%})\end{array}$ & $\begin{array}{c}\text { Total(n=52) } \\
\mathbf{n}(\mathbf{\%})\end{array}$ \\
AML & $14(36.9 \%)$ & $6(42.8 \%)$ & $20(38.4 \%)$ \\
ALL & & & \\
T-cell ALL & $8(21.0 \%)$ & $3(21.4 \%)$ & $11(21.1 \%)$ \\
B-cell ALL & $15(39.5 \%)$ & $5(35.8 \%)$ & $20(38.5 \%)$ \\
Biphenotypic & $1(2.6 \%)$ & - & $1(2 \%)$
\end{tabular}

Table 2: Distribution of AML cases according to immunophenotype

\begin{tabular}{|c|c|c|c|c|c|c|c|c|c|c|c|c|c|c|}
\hline $\begin{array}{c}\text { AML } \\
\text { FAB } \\
\text { subtype }\end{array}$ & $\begin{array}{l}\text { No. } \\
\text { Cases }\end{array}$ & CD34 & $\begin{array}{c}\text { HLA- } \\
\text { DR }\end{array}$ & CD13 & CD33 & $\begin{array}{c}\text { CyM- } \\
\text { PO }\end{array}$ & CD14 & CD 15 & CD117 & CycD & CD7 & CD22 & $\begin{array}{l}\text { CyC- } \\
\text { D79a }\end{array}$ & CD64 \\
\hline AML-M0 & 1 & 1 & 0 & 1 & 1 & 0 & 0 & 0 & 1 & 0 & 0 & 0 & 0 & 0 \\
\hline AML-M1 & 5 & 4 & 4 & 5 & 4 & 3 & 0 & 0 & 3 & 0 & 1 & 1 & 0 & 0 \\
\hline AML-M2 & 10 & 10 & 9 & 10 & 9 & 10 & 0 & 9 & 10 & NA & 0 & 3 & 1 & 0 \\
\hline AML-M3 & 3 & 0 & 0 & 3 & 3 & 3 & 0 & 1 & 2 & NA & 0 & 0 & 0 & 0 \\
\hline AML-M4 & 1 & 0 & 1 & 1 & 1 & 1 & 1 & 0 & 0 & NA & 0 & 0 & 0 & 0 \\
\hline
\end{tabular}

$0=$ Negative, $N A=$ not applicable or not available

Table 3: Distribution of B and T cell ALL cases according to immunophenotype

\begin{tabular}{lccccccccccc}
\hline \multicolumn{1}{c}{ B-Lineage } & No. Cases & CD34 & HLADR & CD10 & CyCD79a & CyCD22 & CD19 & CD 13 & CD33 & TdT \\
$\begin{array}{l}1 . \text { Common ALL } \\
\text { (CD10+) }\end{array}$ & 15 & 15 & 12 & 15 & 10 & 5 & 12 & 3 & 1 & NA \\
$\begin{array}{l}\text { 2. Null-ALL } \\
\text { (CD10- }\end{array}$ & 5 & 3 & 5 & 0 & 5 & 5 & 5 & 0 & 0 & NA \\
\multicolumn{1}{r}{ T-lineage } & No. cases & CD34 & CyCD3 & CD3 & CD7 & CD10 & CD13 & CD33 & HLADR & TdT \\
\hline & 11 & 5 & 11 & 11 & 11 & 0 & 1 & 0 & 0 & NA \\
\hline
\end{tabular}

$0=$ Negative, $N A=$ Not available, cy-Cytoplasmic, $*$ CD10 $+(C A L L A+v e), \uparrow C D 10-(C A L L A-v e)$, 


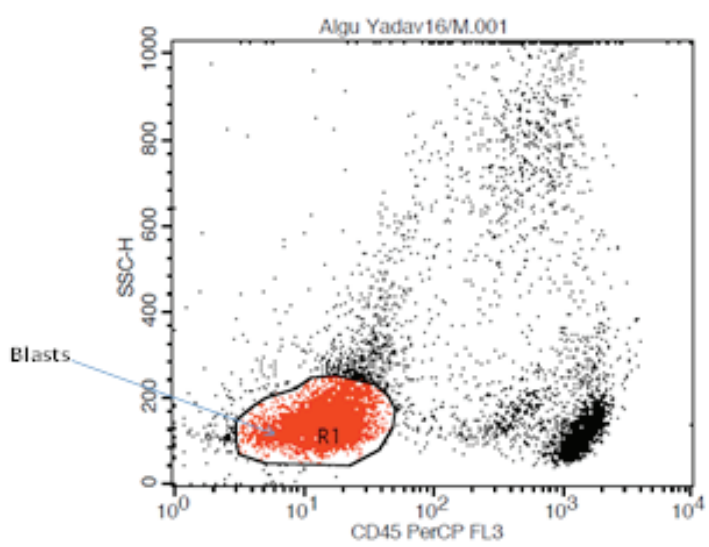

CD45 vs SSC gating dot plot ide ntifie slymphoblast:
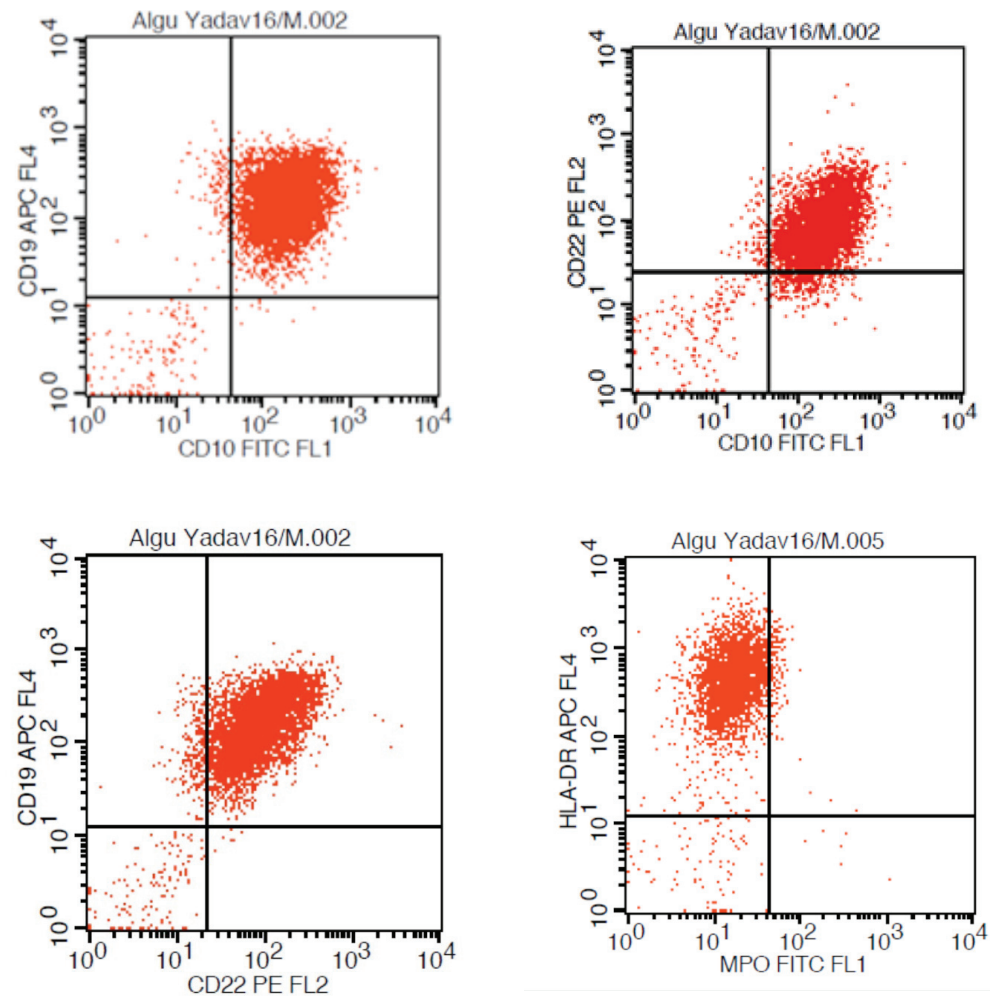

Figure 1: B Cell ALL. The blasts express the B cell markers CD10, CD19 CD22 and HLA-DR. The Cy MPO is negative.

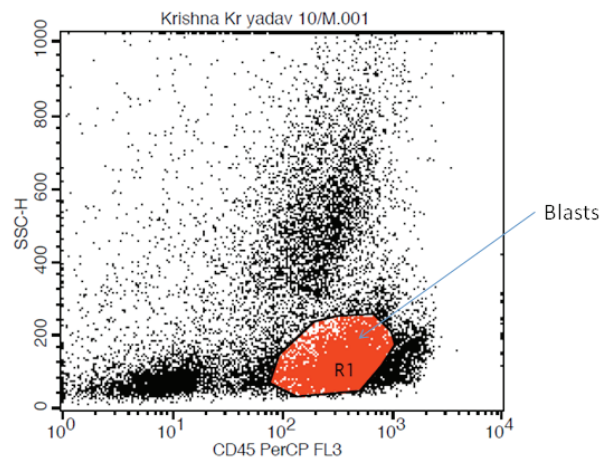

CD45 vs SSC gating dot plot identifies lymphoblasts
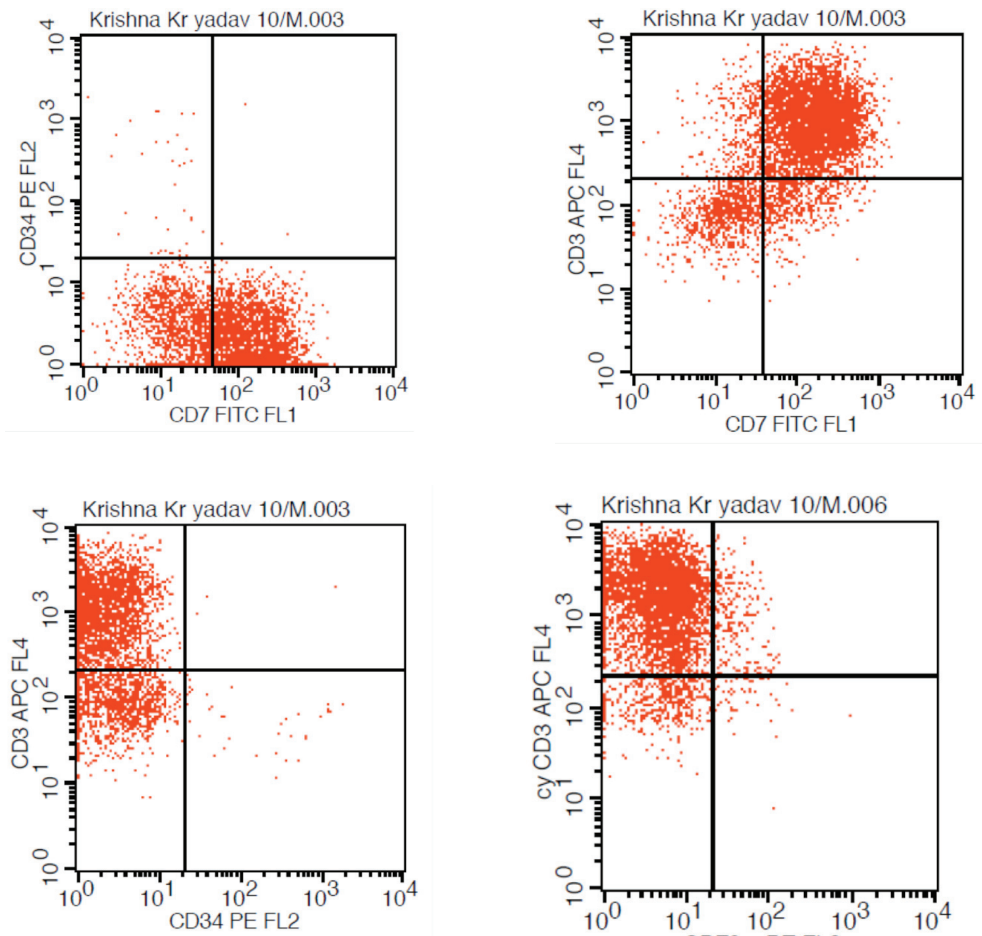

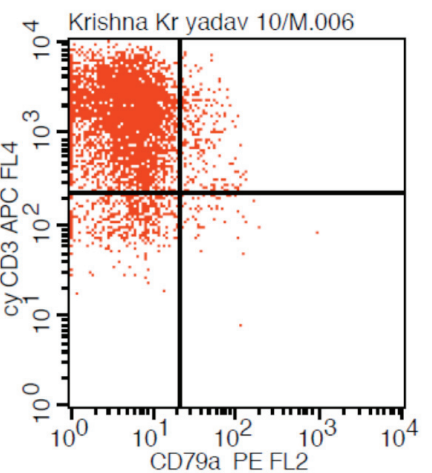

Figure 2: T cell All. The blasts express the T cell markers CD3, cy CD3 and CD7. The B cell marker CD79a is negative. 


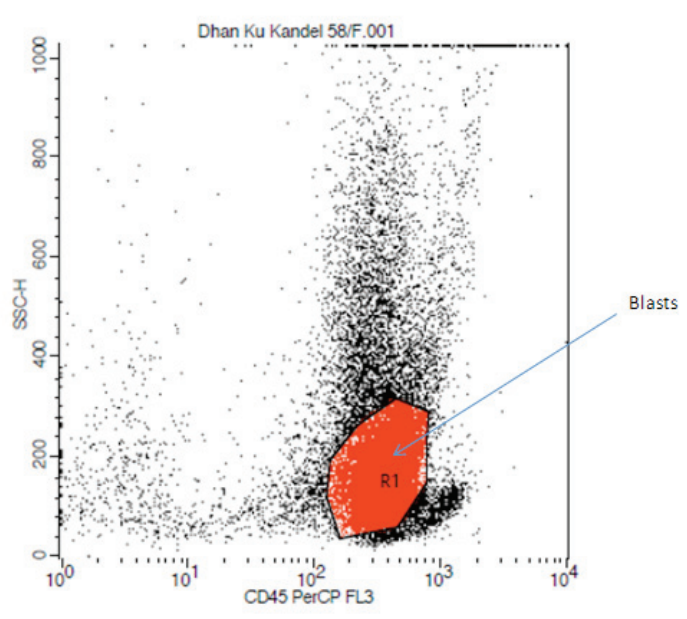

D45 vs SSC gating dot plot identifies myeloblasts

Figure 3: $A M L$.
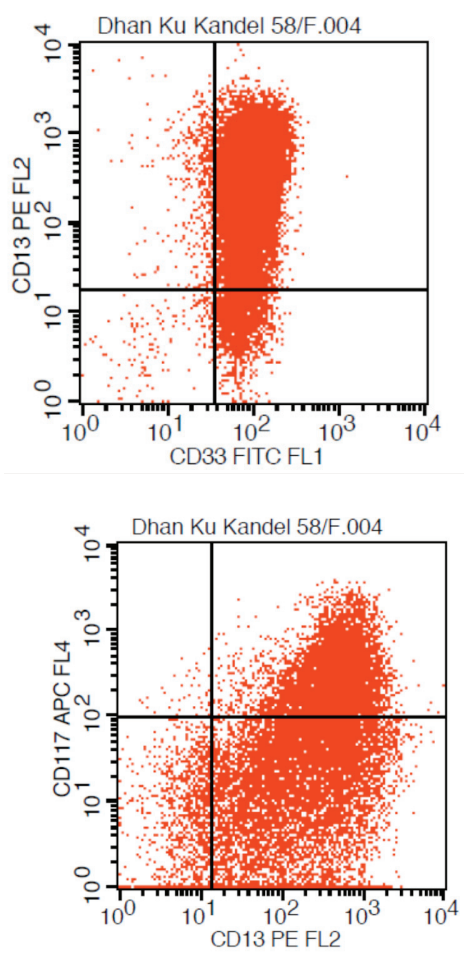
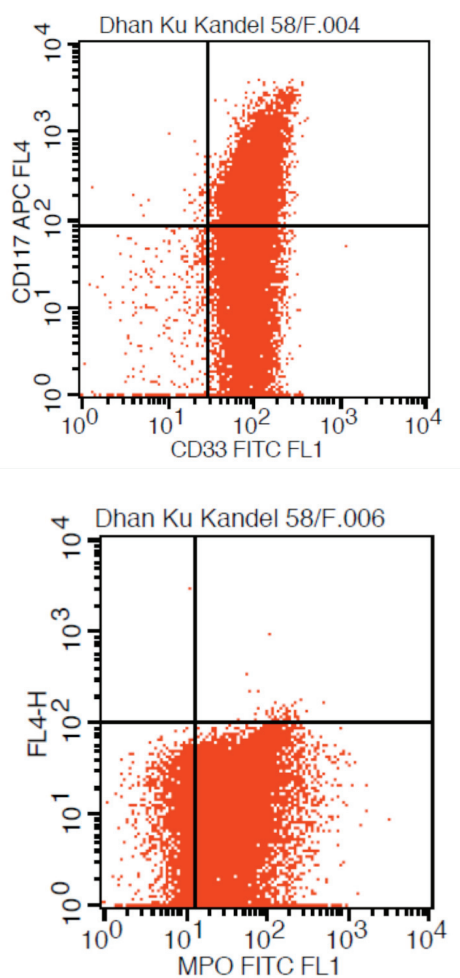

lineage (cyCD3) in acute leukemias by flow cytometry (FC).

\section{DISCUSSION}

Besides morphological and cytochemical studies, immunophenotyping has become an essential diagnostic tool for classification, prognosis, patient management and for disease monitoring of acute leukemias. ${ }^{8-10}$ Acute lymphoblastic leukemia is a major subtype of leukemia in children, where as AML is as common in adults. ${ }^{11}$

In this study cyCD79a, cyCD22, cyCD3, and cyMPO were highly sensitive, specific $\mathrm{B}, \mathrm{T}$, and myeloid markers that were expressed in virtually all cases of B and T cell ALL and in all subtypes of AML. By definition, the diagnosis of AML-M0 require less than $3 \% \mathrm{MPO}+$ and / or $\mathrm{SBB}+$ blasts, expression of myeloid-associated markers, and lack of B/Tlineage-associated antigens (i.e. negativity for cyCD22/ or cyCD79a and cyCD3). ${ }^{6}$ The most significant distinctive immunologic markers between AML-M0 and ALL are CD13, CD33 and CD117, which are typical of M0. ${ }^{12}$ In our study, one AML was classified as M0. The CD34 antigen is expressed by immature blast cells and is thus associated with less differentiated forms of leukemia, whereas the CD13, CD15 and CD33 antigens are expressed by more mature cells and is associated with the more differentiated leukemias. ${ }^{13}$ Identification of AML-M3 is important because it has specific therapy. Having a classical morphology, the promyelocytes show a strong MPO positivity. FC shows a myeloid leukemia (CD13, CD33 and CD117 positivity) along with HLADR negativity. However cytogenetics/ FISH test is must for a confirmation and management of AML-M3. ${ }^{14}$ The combined use of CD34 and HLADR is much helpful in distinguishing AML-M3 from Non- M3 AML's than either of these antigens alone. ${ }^{5}$ Expression of CD14 and CD36 was most often seen in myelomonocytic leukemia. In cases of monocytic differentiation CD13 and CD33 are most commonly expressed while CD34 and CD117 are generally absent. ${ }^{3}$

In present study, incidence of B-ALL (64.5\%) was high in comparison to the Western population 3.0\% (Germany), Ludwig et al. $0.5 \%$ (USA) Rivera et al. ${ }^{15,16}$

An ALL of the B-lymphocyte lineage is assumed if CD22 or CD79a expression is found either cytoplasmic or on the cell surface with the expression of CD19 and HLA-DR. ${ }^{17}$ In childhood ALL, patients with Common-ALL which is CD10+ve ALL do best; while those with Null type ALL which is CD10-ve ALL \{without Common ALL antigen (CALLA) $\}$ and T cell ALL do less well; In adult ALL, patients with Null or Common immunologic subtypes have a poor prognosis. ${ }^{18-20}$

An ALL of the T-lymphocyte lineage is assumed if CD3 expression is found either cytoplasmically or on the cell surface with the simultaneous expression of CD7. T-lineage ALL subtypes can be defined based on the surface expression of CD1a, CD2, CD3, CD4 and CD8. ${ }^{17}$

The aberrant expression of lymphoid antigens on myeloid leukemias was more promiscuous than expression of myeloid antigen on lymphoid leukemias. ${ }^{5}$ The most commonly expressed lymphoid associated antigen on AML was CD7 and similarly myeloid associated antigen on ALL was CD13. This was similar to the results of Putti et al, Den 
Boer et al, Bachir et al and Zheng $\mathrm{J}$ et al. ${ }^{21-23}$

Biphenotypic acute leukemia is an uncommon type of leukemia which probably arises in a multipotent progenitor cell with the capability of differentiating along both myeloid and lymphoid ( $\mathrm{T}$ and $\mathrm{B}$ ) lineages where both types are associated with poor outcomes. Diagnosis of biphenotypic acute leukemia is based on immunophenotyping., ${ }^{3,24}$

\section{CONCLUSION}

A combined classification of the immunophenotype and FAB morphology/cytochemistry was devised for AML and ALL subtyping. Flow cytometric immunophenotyping can be uniquely useful in the diagnosis of AML M0, its differentiation of acute promyelocytic leukemia (APL/ AML M3) from AML M1/M2, correct identification of $T$ and $B$ cell lineage of ALL and diagnosis of biphenotypic leukemia.

\section{ACKNOWLEDGEMENT}

The authors wish to thanks Mr. Madan Pandey for his technical assistance.

\section{REFERENCES}

1. McCulloch EA. Stem cells in normal and leukemic hemopoiesis (Henry Stratton Lecture, 1982). Blood 1983;62:1-13.

2. Chana J. Shani T, Hashmi K. Role of immunophenotyping in diagnosis of acute leukemia. J Coll. Physician Surg. Pak 2000;15860 .

3. Weir EG, Borowitz MJ. Flow cytometry in the diagnosis of acute leukemia. Seminars in hematology 2001;38:124 - 8

4. Huh Yo, Ibrahim S. Immunophenotype in adult acute lymphoblastic leukemia. Hematol Oncol Clin North Am 2000;14:1251-65.

5. Kaleem Z, Crawford E, Pathan MH et al. Arch Pathol Lab Med 2003; 127:42-8.

6. Bennett JM, Catovsky D, Daniel MT et al. Proposal for the classification of acute leukemia.Br. J Haematol 1976;33:451-8.

7. Benc MC, Castoldi G, Knapp W et al. Proposal for the immunological classification of Acute Leukemias. Leukemia 1995;9:1783- 6.

8. Garand R, Robillard N. Immunophenotypic characterization of acute leukemias and chronic lymphoproliferative disorders: Practical recommendations and classifications. Hematol Cell Ther 1996;38:471-86

9. Rubnitz JE, Pui CH. Childhood acute lymphoblastic leukemia. Oncologist 1997;2:374-80.
10. Davis BH, Holden JT, Bene MC et al. 2006 Bethesda International Consensus recommendations on the flow cytometric immunophenotypic analysis of ematolymphoid neoplasia: medical indications. Cytometry B Clin Cytom 2007;72:5-13.

11. Horibe K, Tsukimoto 1, Ohno R. Clinicopathologic characteristics of leukemia in Japanese children and young adults. Leukemia 2001;15:1256-61.

12. Thalhammer- Scherrer R, Mitterbauer G, Simonitsch I et al. The immunophenotype of 325 adult acute leukemias. Am J Clin Pathol 2002;117:380-9.

13. Civin CI, Loken MR. Cell surface antigens on human marrow cells: dissection of hematopoietic development using monoclonal antibodies and multiparameter flow cytometry. Int. J cell cloning 1987;5:1-16.

14. Gujral S, Subramanian PG, Patkar N et al. Role of Flow Cytometry in Diagnosis of Hematolymphoid Malignancies. 4th Conference on evidence management of Cancer in India. 2006. Available from: https://tmc.gov.in/clinicalguidelines/EBM/Vol10/Acute $\% 20$ Lukemia\%20final.pdf

15. Ludwig, WD, Raghavachar A, Theil E. "Immunophenotypic Classification of Acute Lymphoblastic Leukaemia”. Bailliere's Clin Haematol 1994;7:235-55.

16. Rivera GK, Crist WM. "Acute Lymphoblastic Leukaemia”. In: Blood : Principles and Practice of Hematology. Handin R, Stossel R, Lux SE (eds). Lippincott: Philadelphia, PA. 1995;pp743- 82.

17. Rothe G, Schmitz G. European Working Group on Clinica Cell Analysis (EWGCCA). Consensus Document on Leukemia Immunophenotyping. Leukemia 1996;10:877-95.

18. Besa EC, Catalano PM, Kant JA, Jefferies LC. Hematology. NMS, Williams \& Wilkins: Baltimore 1992;179pp.

19. Hoffbrand AV, Pettit JE. Essential Haematology. 3rd ed. Blackwell Scientific Publications: Oxford, London 1993;186pp.

20. Haferlach T, Winkemann M, Petersen RL et al. "New Insights into the Biology of Philadelphia-Chromosome Positive ALL using a combination of May-Grunwald-Giemsa Staining and Fluorescence in situ Hybridization Techniques at Single Cell Level. Br J Haematol 1997:99:452-59.

21. Putti MC, Rondelli R, Cocito MG et al. Expression of myeloid markers lacks prognostic impact in children treated for acute lymphoblastic leukemia: Italian experience in AIEOP-ALL 88-91studies. Blood 1998;92:795-801

22. Den Boer ML, Kapaun P, Pieters R, et al. Myeloid antigen coexpression in childhood acute lymphoblastic leukaemia: relationship with in vitro drug resistance. Br J Haematol 1999;105:876-82.

23. Zheng J, Wang $\mathrm{X}, \mathrm{Hu} \mathrm{Y}$, et al. A correlation study of immunophenotypic, cytogenetic, and clinical features of 180 AML patients in China. Cytometry B Clin Cytom. 2008; 74:25-9.

24. Estella M, Morilla R, Farahat N, et al. Definition of acute biphenotypic leukemia. Recent Advances in the Cytobiology of Leukemias. Haematologica 1997;82:64-6. 